\title{
ESTUDO DAS CONSTRUÇÕES CONDICIONAIS EM DOIS LIVROS DIDÁTICOS SOB A PERSPECTIVA FUNCIONALISTA
}

\section{AN ANALYSIS OF CONDITIONAL CLAUSES IN TWO SCHOOLBOOKS WITH THE SUBSIDIZE UNDER FUNCTIONALISM PERSPECTIVE}

\author{
Rafael Petermann (IFPR/PG-UEM) ${ }^{1}$ \\ Rosangela Jovino Alves (IFPR) ${ }^{2}$
}

\begin{abstract}
RESUMO
Os estudos funcionalistas têm por característica a análise dos elementos linguísticos a partir de seu contexto de uso, considerando a linguagem com um instrumento de interação social e que as estruturas gramaticais são motivadas pelo contexto comunicativo. Do mesmo modo, documentos norteadores do ensino de língua materna no Brasil, como os Parâmetros Curriculares Nacionais e as Diretrizes Curriculares para Educação Básica do Paraná também consideram que a interação é o que faz que a linguagem seja comunicativa, não sendo, por isso, possível que se estude uma língua isolada do ato comunicativo. A partir desse pressuposto, neste trabalho, apresentamos uma análise da abordagem das construções condicionais em atividades presentes em dois livros didáticos a fim de verificar se as definições e atividades apresentadas compreendem a concepção interacionista da linguagem e possibilitam uma reflexão dos elementos linguísticos em situações reais de uso. Este trabalho fundamenta-se na perspectiva teórica do funcionalismo, com ênfase nos trabalhos de Neves (1999; 2011), Castilho (2010) e Neves, Braga, Dall'Aglio-Hattnher (2008) sobre as construções condicionais.
\end{abstract}

PALAVRAS-CHAVE: Funcionalismo; construções condicionais; livro didático.

\begin{abstract}
The Functionalist studies are characterized by analyzing linguistic elements based on their use, considering the language as a social interaction instrument and having grammatical structures used according to the communicative context. In the same way, documents which guide the mother language teaching in Brazil, such as the Parâmetros Curriculares Nacionais and the Diretrizes Curriculares Para Educação Básica no Paraná, also consider the interaction as the reason for language being communicative, therefore not being possible to study the language isolated from the communicative act. Starting from this assumption, we introduce on this article an analysis of how conditional clauses are treated in exercises present in schoolbooks in order to verify if its definition and proposed activities match with the interactionist language approach and if they allow reflexive thinking for the linguistic elements in real use. This essay is based on the Functionalist Perspective, emphasizing some conditional clause studies, such as Neves (1999; 2011), Castilho (2010) and Neves, Braga, Dall'Aglio-Hattnher (2008).
\end{abstract}

KEYWORDS: Functionalism; conditional clauses; textbooks.

\footnotetext{
${ }^{1}$ Mestre em Letras pela Universidade Estadual de Maringá e Professor do Ensino Básico, Técnico e Tecnológico no Instituto Federal do Paraná, Campus Paranavaí. rafael.petermann@ifpr.edu.br

2 Doutora em Letras pela Universidade Estadual de Maringá e Professora do Ensino Básico, Técnico e Tecnológico no Instituto Federal do Paraná, Campus Paranavaí. rosangela.alves@ifpr.edu.br
} 


\section{INTRODUÇÃO}

A complexidade do objeto de estudo da linguística, a linguagem, demanda a necessidade de se fazer uma seleção entre os fenômenos a serem descritos. O ponto de vista funcionalista concebe a linguagem como um instrumento de interação social e estabelece o seu objeto de estudo baseado no uso real, isto é, não há separação entre sistema e uso. Para Pezatti (2011, p. 168), na perspectiva funcional "a linguagem é vista como uma ferramenta cuja forma se adapta às funções que exerce", nesse sentido, a linguagem somente pode ser explicada com base nessas funções.

A concepção de linguagem como interação social, à qual o funcionalismo se afilia, também está presente em documentos oficiais que norteiam as políticas de ensino de língua materna no Brasil como os Parâmetros Curriculares Nacionais e as Diretrizes Curriculares para Educação Básica do Paraná. Nesse sentido, é mister pensar que as condutas de sala de aula de um professor de língua portuguesa que trabalha sob a égide do interacionismo precisam se diferenciar de posturas mais tradicionais, haja vista o conceito de língua aí embutido.

Conceber a língua como fato social implica considerar que ela sofre influência de seus usuários e que, portanto, não é estanque e monolítica, daí a ideia de a sala de aula ser um espaço favorável para reflexões linguísticas, e não um ambiente de reprodução e repetição de prescrições gramaticais. Com efeito, entendemos que os estudos funcionalistas podem contribuir para o processo de ensino e aprendizagem de língua, sobretudo servindo como subsídio teórico à análise linguística (PARANÁ, 2008; MENDONÇA, 2006) em sala de aula.

Ao se considerar que, nas escolas, o livro didático é um dos principais instrumentos de trabalho do professor e do aluno e, também, que o ensino de gramática em geral encontra no conteúdo desses livros o seu subsídio principal, este texto, ancorado nos pressupostos teó ricos do funcionalismo, busca verificar se o trabalho com as construções condicionais em unidades de dois livros didáticos de ensino médio amplamente adotados por escolas públicas do extremo noroeste do Paraná permite o estudo processual e a reflexão sobre esse tipo de construção, ou se são tratadas de forma isolada e/ou privilegiando apenas as prescrições da gramática normativa.

Este artigo organiza-se em três seções. Na primeira, são apresentados aspectos gerais do funcionalismo e sua relação com o ensino. $\mathrm{Na}$ segunda, apresenta-se breve caracterização das construções condicionais com enfoque funcionalista à luz dos estudos de Neves (1999; 2011), Castilho (2010) e Neves, Braga, Dall'Aglio-Hattnher (2008). Por fim, na terceira seção, analisamos atividades propostas em unidades destinadas ao tratamento das construções condicionais em dois livros didáticos: o primeiro trata-se do volume para terceira série do ensino médio da coleção Novas Palavras, de Emília Amaral et.al.; o segundo trata-se do volume destinado à segunda série do ensino médio da coleção Linguagem e Interação, de Faraco, Moura e Marux o Jr.

\section{Aspectos gerais do Funcionalismo}

O Círculo Linguístico de Praga expandiu as discussões acerca do objeto de estudo da linguística. Até então, o objeto tomado pela linguística, tendo em vista as exclusões feitas nas dicotomias saussureanas, tinha na langue (sistema) o objeto por excelência, e essa estratégia teórica, conforme apontam Matelotta e Areas (2003), retirou do âmbito dos estudos linguísticos o interesse por influências sofridas pela estrutura gramatical, provenientes de aspectos do uso concreto das línguas. As considerações feitas pelo Círculo Linguístico de Praga, idealizado por Vilém Mathesius em 1926 e do qual surge a Escola Linguística de Praga, são entendidas como um marco dos primeiros trabalhos funcionalistas. Os trabalhos de um grupo de autores, dentre eles Roman Jakobson, Nikolaj Trubetzkoy e Vilém Mathesius, apresentam noções funcionais dos estudos de fonologia, da morfologia e da sintaxe, respectivamente. Segundo Matelotta e Areas (2003, p. 18), o que caracterizou as análises do Círculo de Praga "foi a adoção de uma noção 
teleológica de função. Para eles, a língua deve ser entendida como um sistema funcional, no sentido de que é utilizada para um determinado fim".

As noções de abordagem funcional difundidas pelo Círculo Linguístico de Praga ocorrem em meio a trabalhos formalistas, mas, a partir delas, os trabalhos funcionalistas se desdobram em correntes funcionalistas heterogêneas, expandem-se e passam a ter destaque pelo mundo. Na Europa, a partir de 1970, ganharam destaque os trabalhos de Halliday, com o desenvolvimento da Gramática Sistêmico Funcional (Systemic Functional Grammar), a Gramática Funcional (Functional Grammar), proposta por Dik, e a Gramática Discursivo-Funcional (Functional Discourse Grammar), proposta por Hengeveld, que pode ser considerada uma ampliação da GF. $\mathrm{Na}$ América, os destaques são os trabalhos de Foley e Van Valin Jr. (1984), com a Gramática de Papel e Referência (Role and Reference Grammar - RRG); e as pesquisas de linguistas constituintes do Funcionalismo da Costa Oeste, do qual fazem parte trabalhos como os de Talmy Givón, Sandra Thompson, Paul Hopper, entre outros.

Os estudos funcionalistas são muitos e heterogêneos em diversos aspectos, mas, de modo geral, todos são assim denominados por contemplarem em seu objeto de estudo a função que os elementos linguísticos assumem em contextos reais de interação verbal. Nessa perspectiva, a análise desses elementos considera suas funções nos níveis de análise linguística, a situação de interação, os participantes dessa interação e o contexto de produção, o que estende a compreensão da língua para além de suas unidades formais. Dessa forma, o interesse de buscar nos contextos de uso motivações para os fatos da língua caracteriza os funcionalistas também por conceberem a linguagem como instrumento de interação social.

Conforme afirma Castilho (2010, p. 64), para o funcionalismo:

A língua é um instrumento de interação social, cujo correlato psicológico é a competência linguística, isto é, a capacidade de manter a interação por meio da linguagem. Segue-se que as descrições das expressões linguísticas devem proporcionar pontos de contato com seu funcionamento em dadas situações. A Pragmática é um marco globalizador, dentro do qual se deve estudar a Semântica e a Sintaxe.

Desse modo, a partir dessa abordagem da concepção de língua, nos pressupostos funcionalistas, de modo geral, a gramática dessa língua não pode ser estudada de modo autônomo, pois ela é influenciada pela situação comunicativa, pelos participantes do discurso e pelo contexto sócio-histórico e cultural de que fazem parte.

Nesse sentido, para compreender a gramática de uma língua em uso, o funcionalismo tende a adotar uma concepção 'pancrônica' de mudança, observando não as mudanças ocorridas em elementos e nas suas relações ao longo do tempo, mas as forças comunicativas e cognitivas que atuam no indivíduo no momento concreto da comunicação e que se manifestam de modo universal. (MARTELOTTA; AREAS, 2003).

Outro fator relevante sobre as abordagens funcionalistas é que o objeto de análise da língua ultrapassa os limites da sentença e se estende para a abordagem de textos. Nesse sentido, Neves, em sua Gramática de Usos do Português, define dois pontos básicos que são adotados na orientação teórica de uma língua em uso: o texto como unidade maior de funcionamento e a multifuncionalidade dos itens linguísticos. Assim, em relação ao texto como objeto de análise,

Nessa consideração de que a real unidade em função é o texto, o que está colocado em exame é a construção de seu sentido, numa teia que é mais que mera soma de partes. Nessa perspectiva, percebe-se que os limites da oração bloqueiam a consideração do funcionamento das unidades da língua. Isso significa que a interpretação das categorias linguísticas não pode prescindir da investigação de seu comportamento na unidade maior - o texto -, que é a real unidade de função. (NEVES, 2011, P. 15) 
Em síntese, com base na caracterização feita até aqui, destaca-se que o modelo funcionalista de análise linguística, nas palavras de Cunha (2012, p. 158), ancora-se em duas propostas básicas: “a) a língua desempenha funções que são externas ao sistema linguístico em si; b) as funções externas influenciam a organização interna do sistema linguístico". Isso significa, vale ressaltar, que o modelo funcionalista de análise linguística está mais voltado ao interesse pelo estudo da relação entre a estrutura gramatical das línguas e os diferentes contextos comunicativos em que elas são usadas.

\subsection{Funcionalismo e ensino de Língua Portuguesa}

Conforme já abordamos anteriormente, o funcionalismo adota a concepção de linguagem como interação social e preocupa-se em estudar sua relação com a sociedade. Halliday (1985 apud DECAT, 2008) considera que os usos é que dão forma ao sistema, do que se depreende a consideração de que nenhuma língua e/ou gramática está completa e acabada, pois não existem línguas uniformes e imutáveis (POSSENTI, 1996). Assim, considerar o aspecto social da língua é considerar que ela é passível de modificações por conta de seus usuários.

Nesse contexto, no que diz respeito à abordagem da gramática na escola, por muito tempo, as aulas de língua materna no Brasil serviam à memorização de regras gramaticais (gramática prescritiva) e a exercícios de repetição e construção de frases com a finalidade do 'bem falar' (PARANÁ, 2008). Todavia, diversos trabalhos como os de Neves (2003; 2010), Mendonça (2006) e Geraldi et.al (2006) foram e vêm sendo desenvolvidos a respeito do ensino de língua na escola e trazem à tona uma mudança substancial na perspectiva do ensino e aprendizagem na área.

Nas palavras de Possenti (2006, p. 33), "o objetivo da escola é ensinar o português padrão, ou talvez mais exatamente, o de criar condiçoes para que ele seja aprendido". Criar condições para que o português padrão seja aprendido demanda não ignorar que o aluno já é conhecedor de uma estrutura linguística complexa e que, portanto, o ensino deve pautar-se na reflexão acerca dessa estrutura a fim de que o aluno pense sobre fatos linguísticos e seja capaz de utilizar a língua de diferentes formas em diversos contextos.

As Diretrizes Curriculares para Educação Básica do Paraná (PARANÁ, 2008) preconizam a língua como fato social e o conteúdo estruturante das aulas de língua portuguesa é o discurso como prática social. Essas diretrizes apontam que as aulas de língua devem pautar-se em práticas discursivas de oralidade, leitura e escrita e elegem como encaminhamento metodológico a "análise linguística", que se configura como um trabalho de "reflexão linguística" que observa a língua em uso e, incluindo morfologia, sintaxe, semântica etc., visa à construção de conhecimentos sobre o sistema linguístico. "O estudo da língua que se ancora no texto extrapola o tradicional horizonte da palavra e da frase” (PARANÁ, 2008, p. 60).

É importante salientar que a "comunicação verbal só é possível por algum gênero textual situado em algum domínio discursivo" (DECAT, 2008, p. 172), assim o 'texto' é a materialização do discurso, portanto é em torno dele que deve girar a aula de língua, não o tomando como pretexto para ensinar normas, mas o tomando como objeto de estudo para compreender e agir reflexivamente sobre os elementos linguísticos que estão ali postos, verificando de que forma eles contribuem para o sentido.

Entendemos, então, que os fundamentos teórico-metodológicos presentes nas Diretrizes Curriculares do Estado do Paraná estão em consonância com o escopo dos estudos funcionalistas, pois ambos concebem ontologicamente a linguagem como fato social e, por isso, demandam que a reflexão linguística esteja pautada em análises acerca do "funcionamento" das

${ }^{1}$ grifo nosso. 
estruturas linguísticas e seus procedimentos de significação nos diferentes gêneros discursivos nos diversos campos de atuação social.

Dessa forma, pensar uma aproximação entre o funcionalismo e o ensino de língua materna significa, para o professor, assumir atitudes mais coerentes com a concepção de linguagem tomada em documentos oficiais e na ciência linguística contemporânea tais como: i) entender a língua como fato social sujeito à interferência dos falantes; ii) metodologia reflexiva, baseada na observação de fatos linguísticos em situações de uso concreto da língua (textos), tirando conclusões sobre regularidades/regras; iii) texto como unidade privilegiada. (MENDONÇA, 2006).

\section{Breves considerações sobre as construções condicionais na perspectiva funcional}

As construções condicionais nas línguas naturais não possuem uma definição filosófica ou linguística satisfatória. Haiman (1978 apud NEVES, 1999) considera que o único critério para identificação dos membros da classe é a conjunção em inglês if. Assim, em português, a análise dessa classe de construções se daria na análise das orações iniciadas pela conjunção se e suas equivalentes (NEVES, 1999; 2011).

$\mathrm{Na}$ abordagem tradicional, presente em gramáticas normativas, as construções condicionais fazem parte das denominadas orações subordinadas adverbiais. Segundo Rocha Lima (1972), essas orações equivalem a um advérbio e figuram como adjunto adverbial da oração a que se subordinam. Quando desenvolvidas, começam por conjunção subordinativa, segundo a qual são classificadas; quando reduridas, aceitam - muitas delas - as formas infinitiva, gerundial e participial. $O$ autor classifica as orações subordinadas adverbiais em: causais, concessivas, condicionais, conformativas, comparativas, consecutivas, finais, modais, temporais e proporcionais.

Os estudos funcionalistas expandem essa abordagem tradicional e apresentam os valores dessas construções a partir de contextos reais de uso. De acordo com Neves (1999; 2011), nas construções condicionais, a proposição subordinada é chamada de prótase e a principal chamada de apódose, e sua organização se dá basicamente sob as formas: [se] + [oração condicional] + [oração principal], como se vê em (01); ou [oração principal] + [se] + [oração condicional], como se vê em (02).

\section{(01) Se eu morresse amanhã/ viria fechar meus olhos minha triste irmã}

(02) Minha mãe de saudades morreria/ se eu morresse amanhã

Com relação às condições expressas, Neves $(1999$; 2011) chama a atenção para o fato de que tradicionalmente a relação que se instaura entre o conteúdo da condicional (prótase) e o conteúdo da condicionada (apódose) é uma relação do tipo: (prótase - condição para realização) x (apódose - consequência - resultado da resolução da condição enunciada).

Neves (2011) adverte, porém, que as relações expressas nas condicionais não se limitam à ideia ora apresentada. Segundo ela, do ponto de vista da organização da informação no texto, verifica-se que as construções condicionais antepostas constituem, em geral, um tópico discursivo. "Sendo assim, as orações condicionais formam uma espécie de moldura de referência em relação à qual a oração principal é factual, ou apropriada. Além disso, frequentemente nessas orações está uma informação que não é dita como novidade". (NEVES, 2011, p. 833)

Tendo em vista a relação que tradicionalmente se instaura entre prótase e apódose (condição para realização x consequência/ resultado), Neves, Braga, Dall'Aglio-Hattnher (2008, p. 958) definem três subtipos de construções condicionais:

- real/factual: dada a realização/verdade de $p$, segue-se, necessariamente, a realização/verdade de $q$; 
- irreal/contrafactual: dada a não realização/falsidade de $p$, segue-se, necessariamente, a não-realização/falsidade de $q$;

- eventual/potencial: dada a eventualidade de $p$, segue-se a potencialidade de $q$.

O primeiro subtipo caracteriza-se pelo fato de que o elemento se encabeça algo que é verificado:

(03) Se meus antepassados vieram/ é claro que os dele vieram também.

No caso de (03), a oração 'se meus antepassados vieram' caracteriza-se como algo verificado, isto é, é dada como certa a vinda dos antepassados. Do mesmo modo, a oração 'é claro que os dele vieram também' também constitui algo verificado. Segundo Castilho (2010), nesse subtipo, o enunciado da prótase é concebido como real e, em função disso, o enunciado da apódose é tido como uma consequência necessária e igualmente real. Essas condicionais remetem para o mundo do já sabido e normalmente apresentam o esquema [se + indicativo/indicativo].

De acordo com Neves (2011), construções como (03), mesmo iniciadas pela conjunção se, prototípica de condicionalidade, mesclam com essa noção um matiz de contraste.

Outros exemplos do subtipo factual/real:

(04) Se eu te digo éporque tem!

(05) Se ela não está contigo é porque não soubeste dialogar com ela.

No segundo subtipo, as contrafactuais/ irreais, embora a relação mais expressa seja também a de fato x conclusão, o que se observa é que a relação conclusiva se dá com a inversão da polaridade da prótase e da apódose. Note-se o exemplo (06):

(06) se o Pica-pan tivesse comunicado a polícia, nada disso teria acontecido.

Com relação a (06), tem-se: prótase positiva: Se o Pica-pau tivesse comunicado a polícia; fato com polaridade negativa: Pica-Pau não comunicou a polícia./apódose negativa: nada disso teria acontecido; conteúdo asseverado positivo: tudo isso aconteceu.

Castilho (2010) define as condicionais contrafactuais como aqueles em que a prótase encerra uma informação falsa, a qual é contrária à realidade. O esquema encontrado nesse subtipo, segundo o autor, é [se + subjuntivo/forma em -ria].

O terceiro subtipo, condicionais eventuais/potenciais, são construções cuja prótase repousa sobre eventualidade; o enunciado da apódose, no caso, é tido como certo, desde que satisfeita a condição enunciada, como se observa em (07):

\section{(07) A dor no peito emudecera ao menos/ se eu morresse amanhã.}

Embora não sendo muito comum o uso da forma verbal no pretérito mais que perfeito do indicativo na apódose, observa-se que esse enunciado corresponde a algo tido como certo desde que a condição da prótase (morrer amanhã) seja satisfeita. De acordo com Castilho (2010), nas condicionais eventuais, também denominadas potenciais, a prótase é eventual, e a apódose confirma a hipótese anterior desde que a condição verbalizada na prótase seja satisfeita.

No que tange ao esquema modo-temporal das construções condicionais, numa indicação geral, Neves (2011, p. 848) observa que na oração condicional a conjunção se inicia tanto orações com formas verbais no indicativo como no subjuntivo, porém as demais conjunções condicionais (caso, dado que, desde que, uma vez que, sem que, contanto que, a menos que, a não ser que) só se constroem com formas verbais no subjuntivo; na oração principal ocorre o 
indicativo, a não ser que alguma modalização leve ao subjuntivo. Quanto ao tempo, a conjunção se e aquelas em que o se vem focalizado (salvo se, exceto se) iniciam orações de presente, passado e futuro. As outras conjunções condicionais iniciam orações de presente e de passado. A seguir é apresentada a correção modo-temporal entre o verbo da matriz e o verbo da condicional por subtipo segundo Neves; Braga; Dall'Aglio-Hattnher, 2008:

\begin{tabular}{|c|c|c|c|c|}
\hline $\begin{array}{l}\text { SENTENÇA- } \\
\text { NÚCLEO } \\
\text { (APÓDOSE) }\end{array}$ & $\begin{array}{c}\text { SENTENÇA CONDICIONAL } \\
\text { (PRÓTASE) }\end{array}$ & REAL & IRREAL & EVENTUAL \\
\hline \multirow{5}{*}{$\begin{array}{l}\text { Presente } \\
\text { do indicativo }\end{array}$} & Presente do indicativo & $\mathrm{X}$ & & $\mathrm{X}$ \\
\hline & Futuro do subjuntivo & & & $\mathrm{X}$ \\
\hline & Presente do subjuntivo & & & $\mathrm{X}$ \\
\hline & Pretérito perfeito do indicativo & $\mathrm{X}$ & & \\
\hline & $\varnothing$ & & & $\mathrm{X}$ \\
\hline \multirow{2}{*}{$\begin{array}{l}\text { Futuro do } \\
\text { presente }\end{array}$} & Futuro do subjuntivo & & & $\mathrm{X}$ \\
\hline & Presente do indicativo & $\mathrm{X}$ & & \\
\hline \multirow{2}{*}{$\begin{array}{l}\text { Futuro do } \\
\text { pretérito }\end{array}$} & Pret. Imperf. do subjuntivo & & $\mathrm{X}$ & $\mathrm{X}$ \\
\hline & Futuro do subjuntivo & & & $\mathrm{X}$ \\
\hline \multirow{2}{*}{$\begin{array}{c}\text { Pretérito } \\
\text { imperfeito do } \\
\text { indicativo }\end{array}$} & Pretérito imperfeito do subjuntivo & & & $\mathrm{X}$ \\
\hline & Pretérito imperfeito indicativo & $\mathrm{X}$ & & \\
\hline \multirow{2}{*}{$\begin{array}{l}\text { Pretérito } \\
\text { perfeito do } \\
\text { indicativo }\end{array}$} & Pretérito perfeito do indicativo & $\mathrm{X}$ & & \\
\hline & Presente do indicativo & $\mathrm{X}$ & & \\
\hline Futuro pretérito & Pretérito imperfeito do subjuntivo & & $\mathrm{X}$ & \\
\hline Futuro presente & Preterito perfeito do indicativo & $\bar{X}$ & & \\
\hline $\begin{array}{l}\text { Presente } \\
\text { contínun }\end{array}$ & Futuro do subjuntivo & & & $\mathrm{X}$ \\
\hline Pretérito & Futuro so subjuntivo & & & $\mathrm{X}$ \\
\hline$\varnothing$ & & $\mathrm{X}$ & $\mathrm{X}$ & $\mathrm{X}$ \\
\hline
\end{tabular}

Além de fazerem parte de construções condicionais nas quais há a presença de uma conjunção, as categorias de tempo e modo verbal também podem, por si só, expressar a condição. Conforme afirma Leão (1961, apud Castilho, 2010), no período hipotético propriamente dito, a ideia de condição, além de ser expressa pela conjunção, pode ser expressa também pelo tempo e pelo modo dos verbos.

(8) O patrão é porque não tem força. Tivesse ele os meios e isto viraria um fazendão. 
Segundo Castilho, em 8, mesmo sem a presença da conjunção, o modo verbal no subjuntivo (tivesse) mantém o efeito da condição.

Enfim, é possível observar que as construções condicionais reúnem uma série de especificidades. Nesse sentido, a visão de Neves (1999; 2011), de caráter funcionalista, discutida nesta seção, motiva a reflexão sobre a língua em uso e leva ao objetivo deste trabalho, ou seja, verificar a abordagem desses elementos gramaticais em duas unidades de livros didáticos. A partir desse exercício de análise, busca-se verificar se os livros têm apresentado uma abordagem ampla dos conceitos linguísticos e se os exemplos são baseados em usos cotidianos da língua. Desse modo, objetiva-se analisar se esses materiais, assim como sugerem documentos oficiais, concebem a língua como fato social e buscam a reflexão e análise linguística, ou se resumem na memorização de regras e na reprodução dessas regras por meio de exercícios.

$\mathrm{Na}$ seção seguinte, apresentamos uma análise do trabalho com as construções condicionais nos livros didáticos Novas Palavras e Linguagem e Interação, ambos destinados ao Ensino Médio e inseridos no Programa Nacional para Livro no Ensino Médio.

\section{Exercício de análise das construções condicionais em livros didáticos}

O primeiro exercício analítico é feito a partir das atividades presentes no capítulo 3, "Orações subordinadas adverbiais", que se encontra na seção "Gramática" do volume destinado à terceira série do ensino médio da coleção Novas Palavras, produzida por Emília Amaral et.al. O livro em questão é a $2^{a}$ edição, de 2005, e fez parte do catálogo do Programa Nacional do Livro para Ensino Médio (PNLEM) do triênio 2009-2011.

Segundo o resenhista do catálogo do PNLEM 2009, essa coleção apresenta os conteúdos linguísticos em uma perspectiva tradicional, embora contraponha em alguns momentos regras normativas e regras de uso efetivo da língua. Ainda conforme avaliação do resenhista da coleção, a descrição estrutural da língua é feita de forma calcada em modelos tradicionais, além de haver certo descompasso entre a maneira de descrever esses aspectos e a forma de explorar criativamente fatos linguísticos nas atividades propostas.

No que diz respeito às definições das construções condicionais nesse livro didático, são apresentadas em duas páginas, com caráter estrutural, nove classificações de orações subordinadas adverbiais. As construções condicionais são colocadas em um quadro ao lado das outras classificações das orações subordinadas adverbiais, a saber: causais, consecutivas, conformativas, concessivas, comparativas, finais, proporcionais e temporais. Nesse quadro, são apresentadas as principais conjunções que ocorrem nessas orações (se, a menos que, contanto que, desde que); é apresentada, também, a circunstância expressa por esse tipo de oração (exprime a condição necessária para a ocorrência do fato referido na oração principal); e, por último, é apresentado um exemplo dessas orações (Ele virá, contanto que tu peças).

A subseção "Atividades" é precária com relação à presença de textos e situações de uso concreto da língua. Ela intercala atividades de cunho estruturalista com atividades que pretendem levar o aluno a refletir sobre fatos da língua, conforme se observa nas atividades que são transcritas abaixo:

1. Nos itens a seguir, reescreva a frase relativa a cada período, completando-a com uma das palavras do quadro, de modo a indicar adequadamente a relação de sentido entre a oração principal e a subordinada adverbial.

\begin{tabular}{|lll|}
\hline Comparação & tempo finalidade & proporção concessão \\
Causa & condição & conformidade consequência \\
\hline
\end{tabular}


a. Nós iríamos ao show, se o ingresso não custasse muito caro. Oração principal Oração subord. Adverbial A oração adverbial exprime a [] de ocorrência do fato apresentado na principal.

b. Fiquei sabendo o preço do ingresso, quando conversei com Oração principal Oração subord. Adv. um amigo sobre o show. $[\ldots]$

2. As orações adverbiais sublinhadas em cada grupo de frases abaixo, embora sejam introduzidas por uma mesma forma de conjunção, expressam circunstâncias diferentes. Associe a cada oração uma das classificações do quadro.

a. 1. Desde que ele se mudou para Goiás, nunca mais voltou à cidade natal.

2. A biblioteca lhe emprestará o livro, desde que você o devolva até sexta-feira.

3. Desde que o documento é falso, é melhor entregá-lo à polícia.

$[\ldots]$

(AMARAL, et.al., 2005, p. 186)

$\mathrm{Na}$ atividade 1, é possível perceber o caráter normativo que se preocupa apenas com a classificação das orações segundo sua nomenclatura, ou seja, sua taxonomia. A atividade 2, por outro lado, exige do aluno certa reflexão acerca de um fato linguístico. Embora o enunciado da atividade 2 apresente para o aluno o fato de algumas orações serem introduzidas pela mesma conjunção com sentidos diferentes, a atividade não contempla o que foi trabalhado na apresentação de conceitos, pois, no quadro de classificação de orações, aparecem as principais conjunções que ocorrem em cada tipo de oração, mas não há nada sobre a possibilidade de uma mesma conjunção assumir diferentes valores dependendo do contexto. No quadro, podemos verificar que uma mesma conjunção ou locução conjuntiva, por exemplo "desde que" (temporal e condicional), ocorre em mais de um tipo de oração. Entretanto, não há reflexão sobre isso. Apenas no exercício supracitado, o contexto é apresentado como um dos elementos que podem alterar o valor do elemento linguístico.

A subseção seguinte, "Da teoria à prática", apresenta uma atividade interessante no que diz respeito à reflexão sobre os efeitos de sentido que certas construções podem gerar:

2. Imagine que o técnico de um time de futebol esteja sendo muito criticado pela torcida, em função da maneira como ele vem dirigindo o time. Imagine ainda que, a respeito desse fato, ele emita uma destas duas opiniões:

1. Quando o time conquistar o campeonato, a torcida voltará a me apoiar.

2. Se o time conquistar o campeonato, a torcida voltará a me apoiar.

a. Que circunstâncias exprimem as orações adverbiais presentes nesses dois períodos? 
b. Em qual dos dois casos o técnico revela-se mais confiante com relação ao futuro do time? Justifique.

(AMARAL, et.al., 2005, p. 186)

Nessa atividade, o aluno deve refletir sobre as circunstâncias expressas por cada uma das orações adverbiais (a saber, temporal e condicional) e seu efeito de sentido. Certamente, uma atividade com esse caráter propicia muito mais a análise linguística do que a atividade 1 apresentada anteriormente. Por meio dela, é possível levar o aluno a refletir que a escolha entre uma ou outra opção pelo técnico não é simplesmente uma questão de sistema, mas de intencionalidade do falante.

O que se observa quanto ao trabalho com as construções condicionais nessa coleção é que ela oferece algumas atividades de análise linguística, mas essas atividades são desvinculadas entre si, o que implica dizer que não há um processo de estudo e compreensão processual dessas construções, visto que as atividades são pontuais e isoladas.

O segundo exercício analítico toma como objeto o capítulo 11, "Imagem e palavra (I): o anúncio publicitário", que está no volume destinado à segunda série do ensino médio da coleção Linguagem e Interação, produzida por Faraco, Moura e Maruxo Jr. Como o capítulo é bastante extenso e o que interessa a esta análise é a maneira como as construções condicionais são trabalhadas nas atividades propostas para os estudantes, analisamos mais detidamente a seção "Língua - análise e reflexão" do capítulo 11. O livro que serve a esta análise é a primeira edição da coleção, a qual integra o Programa Nacional do Livro Didático (PNLD) do triênio 2012-2014.

Segundo consta na resenha da coleção no catálogo do PNDL 2012, o trabalho com os conhecimentos linguísticos se dá nas seções "Língua - análise e reflexão", "Prática de linguagem" e "Gramática textual". A perspectiva de abordagem abrange os níveis morfossintático e semântico das unidades linguísticas, associados à sua funcionalidade no âmbito do texto e da situação de comunicação.

A seção "Língua - análise e reflexão", antes de apresentar qualquer nomenclatura, retoma o texto Negrinha, de Monteiro Lobato, já trabalhado e discutido nas unidades anteriores do material. A seguir, apresentamos a transcrição de uma atividade proposta a partir da leitura do texto:

Vamos aqui retomar o estudo da argumentação e você vai notar como é possível argumentar a partir da expressão da hipótese e da condição.

$01 . \quad$ Leia o enunciado:

"Se negrinha ouvisse uma palavra de carinho, que ideia faria de si?"

a) Identifique o trecho desse enunciado que exprime uma hipótese e explique- a em seu caderno.

b) Nesse trecho que você localizou, há verbo? Em caso afirmativo, em qual tempo e modo verbal ele é empregado?

c) Quantas orações formam esse enunciado? Quais são elas?

d) Identifique a conjunção que introduz a oração que exprime hipótese.

(FARACO; MOURA; MARUXO JR., 2010, p. 313)

Nessa atividade o aluno deve refletir a respeito de um certo padrão das construções condicionais, reconhecendo, por exemplo, sua realização nos âmbitos da "condição + resultado" (NEVES, 1999; 2011). Destaca-se que, embora as perguntas tenham como foco o entendimento 
de um padrão, a questão a) demanda refletir sobre a forma que a oração condicional coopera na produção de sentido, não só da sentença, mas no próprio conto. Após essa atividade, em que o aluno supostamente terá evidenciado a relação de sentido de hipótese e a marca da conjunção se iniciando a condicional, o livro destaca um quadro que apresenta diversas possibilidades de construções condicionais iniciadas com se em diferentes tempos e modos e, também, seus efeitos e nuances de sentido. O que se verifica, porém, é que praticamente todas as nuances de sentido demonstradas remontam à ideia de hipótese. Segundo Neves (1999; 2011), as relações expressas pelas condicionais se dão no âmbito da 'condição x resultado' e eventualmente servem como tópico, ou seja, apresentam o tema sobre o qual se desenvolvem as informações.

Outra atividade do material pretende levar o aluno a verificar como o uso de determinados tempos e modos verbais geram efeitos de sentidos diferentes. A seguir, está a transcrição da atividade:

02. Leia as frases a seguir e copie no caderno a oração subordinada adverbial condicional de cada uma delas. Identifique o modo e o tempo do verbo dessa oração e o efeito de sentido produzido pelo conjunto oração subordinada+ oração principal. [...]

a) Se você já assinou o contrato de compra do apartamento, deve ter se arrependido, pois a documentação dele está com problemas.

b) Se conversássemos com o casal, eles já teriam resolvido os problemas de relacionamento.

c) Se o diretor não demitir muitos funcionários, a empresa não sobreviverá.

d) Se Negrinha tivesse expressado seus sentimentos, com certeza não teria morrido tão cedo.

(FARACO; MOURA; MARUXO JR., 2010, p. 315)

Após atividades cujo foco é o estudo da forma e dos efeitos de sentido das construções condicionais iniciadas pela conjunção se, o material mostra como é possível ampliar as possibilidades de construção a partir de outras conjunções. Dessa forma, conforme assinala a resenha do catálogo do PNLD 2012, as atividades propostas oferecem abordagem dos fatos e das categorias gramaticais e contemplam os diversos níveis de análise, articulando-se em progressão de complexidade, ou seja, possibilita aprendizagem de modo processual.

Na seção "Prática de Linguagem", o que chama atenção é o fato de que o aluno é colocado diante de atividades que exigem dele o uso das construções condicionais sem, no entanto, preocupar-se com nomenclatura. A seguir, está um modelo de atividade dessa seção:

01. Leia estas hipóteses: $\mathrm{O}$

que aconteceria se:

... o mundo acabasse amanhã?

... não houvesse mais guerra?

... as geleiras derretessem em menos de 24 horas?

Imagine o que aconteceria se cada uma delas se concretizasse:

a. Quais seriam, em cada caso, as consequências econômicas, políticas, sociais, morais etc.? 
b. Produza por escrito uma descrição de todas essas hipóteses. Utilize a maior quantidade possível de expressões de hipóteses.

c. Compara seu texto com o de um colega e decidam quem imaginou as consequências/situações mais surpreendentes.

(FARACO; MOURA; MARUXO JR., 2010, p. 318)

Nessa atividade, espera-se que, tacitamente, o aluno utilize as construções condicionais, sobre as quais já trabalhou, para produzir suas respostas.

Com efeito, documentos orientadores do ensino de Língua Portuguesa, como as Diretrizes Curriculares do Paraná, estando alinhados a perspectivas funcionalistas para o encaminhamento da reflexão sobre fenômenos da língua, apontam para a necessidade de que o fazer pedagógico, e por extensão o próprio material didático, estejam atentos a situações de uso da língua que evidenciem as formas de significar. Nesses termos, entendemos que as atividades apresentadas na coleção Linguagem e Interação favorecem o trabalho com a reflexão linguística sobre as construções condicionais. É inegável, porém, que o saber linguístico do professor deve dar-lhe condições de trabalhar de modo eficaz com qualquer material que tenha à disposição.

\section{CONSIDERAÇÕES FINAIS}

Sabe-se que ao longo dos anos a mudança do ponto de vista da linguística (re)configurou o seu próprio objeto de estudo, a linguagem. E é inegável que essas mudanças se refletiram nas políticas e documentos oficiais que orientam o ensino de língua na educação básica.

Os Parâmetros Curriculares Nacionais e as Diretrizes Curriculares para Educação Básica do Paraná concebem a língua como fato social e orientam o trabalho de ensino e aprendizagem nessa área em uma perspectiva interacionista, o que demanda condutas e posturas específicas em sala de aula, com ênfase para a reflexão linguística tendo como pano de fundo contextos de uso real, isto é, o contato com uma diversidade de gêneros textuais.

Nesse sentido, objetivamos neste trabalho verificar em dois materiais didáticos destinados ao ensino médio com grande adesão em escolas do extremo noroeste do Paraná, se a abordagem dada às construções condicionais nas atividades propostas aos alunos propiciava a reflexão linguística e possibilitavam o estudo processual dessa forma de construção, ou se eram tratadas de forma desconexa e isolada.

Constatou-se que na coleção Novas Palavras, a abordagem sobre as construções condicionais se dá com o foco na taxonomia dos elementos linguísticos com atividades que ora exigem apenas domínio de regras gramaticais para que se domine a norma padrão da língua ora solicitam alguma reflexão linguística. Vale destacar que nesta coleção as construções condicionais são abordadas em meio a outras nove classificações das chamadas "orações adverbiais", logo, o trabalho com nuances e efeitos de sentido que podem ser conseguidos com outras conjunções condicionais não tem tanto espaço.

Por outro lado, a coleção Linguagem e Interação mostra um tratamento mais detalhado com as construções condicionais e possibilita o estudo processual e vinculado a textos e situações de uso, pois as atividades permitem a reflexão linguística, considerando inclusive as diversas possibilidades de construções modalizações a fim de determinados efeitos de sentido.

Outra constatação desta pesquisa é que os materiais didáticos, mesmo aquele com teor mais estruturalista, apresentam atividades pontuais que possibilitam a análise linguística, todavia compete ao professor e ao seu saber linguístico atuar nessas situações de forma eficaz e levar os 
alunos a reconhecerem possibilidades linguísticas e não apenas a 'cumprirem as atividades do livró'.

Por fim, esperamos que os resultados apontados por este estudo possam contribuir para reflexão da prática pedagógica de professores de língua portuguesa, bem como com a forma com que trabalham com o livro didático e o analisam em períodos de escolha. Esperamos também que este estudo colabore para uma compreensão maior sobre o funcionalismo e sobretudo no que tange à sua compreensão de língua como algo vivo e mutável

\section{REFERÊNCIAS BIBLIOGRÁFICAS}

AMARAL, Emília; et.al. Novas Palavras: língua portuguesa: ensino médio. Volume 3. 2.ed. São Paulo: FTD, 2005.

BRASIL. Parâmetros Curriculares Nacionais para o Ensino Médio: linguagens, códigos e suas tecnologias. Brasília: Ministério da Educação, 1998.

Lingua Portuguesa: catálogo do Programa Nacional do Livro para o Ensino Médio: PNLEM/2009. Brasília: Ministério da Educação, Secretaria de Educação Básica, 2008.

Guia de livros didáticos: PNLD 2012: Língua Portuguesa. Brasília: Ministério da Educação, Secretaria de Educação Básica, 2011.

CASTILHO, Ataliba T. de. Nova Gramática do Português Brasileiro. São Paulo: Editora Contexto, 2010.

CUNHA, Maria Angélica Furtado. Funcionalismo. in MARTELOTTA, Mário Eduardo (org.). Manual de Linguística. 2.ed. São Paulo: Contexto, 2012.

CUNHA, Maria Angélica Furtado da; COSTA, Marcos Antônio; CEZARIO, Maria Maura. Pressupostos teóricos fundamentais. in. CUNHA, Maria Angélica Furtado da; OLIVEIRA, Mariangela Rios de; MARTELOTTA, Mário Eduardo (orgs.) Linguística funcional: teoria e prática. Rio de Janeiro: DP\&A, 2003. p. 30-55.

DECAT, Maria Beatriz Nascimento. A relevância da investigação dos processos linguísticos, numa abordagem funcionalista, para os estudos sobre os gêneros textuais. in ANTONIO, Juliano Desiderato (org.) Estudos descritivos do português:

história, uso, variação. São Carlos: Editora Claraluz, 2008.

FARACO, Carlos Emílio; MOURA, Francisco Marto de; MARUXO JR., José Hamilton. Lingua Portuguesa: linguagem e interação. Volume 2. São Paulo: Ática, 2010.

FUZA, Angela Francine; ANTONIO, Juliano Desiderato. As construções condicionais em uma perspectiva funcionalista no livro didático de língua portuguesa. in. Voos Revista Polidisciplinar Eletrônica da Faculdade Guairacá. v. 01. jul.2009, p.23-34.

GERALDI, João Wanderley (org.) O texto na sala de aula. 4.ed. São Paulo: Ática, 2006.

MARTELOTTA, Mário Eduardo; AREAS, Eduardo Kenedy. A visão funcionalista da linguagem no século XX. in. CUNHA, Maria Angélica Furtado da; OLIVEIRA, Mariangela Rios 
de; MARTELOTTA, Mário Eduardo. (orgs.) Linguística funcional: teoria e prática. Rio de Janeiro: DP\&A, 2003.p. 17-28.

MENDONÇA, Márcia. Análise linguística no ensino médio: um novo olhar, um outro objeto. In: BUNZEN, Clécio; MENDONÇA, Márcia (orgs.). Português no ensino médio e formação do professor. 2 ed. São Paulo: Parábola, 2006.

NEVES, Maria Helena de Moura. As construções condicionais. in. (org.)

Gramática do português falado. Volume 2. Campinas: Editora UNICAMP, 1999. p. 497-544.

As conjunções condicionais. As construções condicionais. in. Gramática de usos do português. 2.ed. São Paulo: Editora Unesp, 2011. p.829-861.

- Linguagem escolar. Alguns aspectos da gramática de usos na escola. in. 2010. p. 171- 196. Ensino de língua e vivência de linguagem: temas em confronto. São Paulo: Contexto,

NEVES, Maria Helena de Moura; BRAGA, Maria Luiza; DALL'AGLIO HATTNHER, Marize Mattos. As construcões hipotáticas. In: ILARI, Rodolfo; NEVES, Maria Helena de Moura (Orgs.) Gramática do Português Culto Falado no Brasil: classes de palavras e processos de construção. vol. II, Campinas, SP: Editora da Unicamp, 2008.

PARANÁ. Diretrizes Curriculares da Educação Básica: língua portuguesa. Curitiba: SEED, 2008.

PEZATTI, Erotilde Goreti. O funcionalismo em linguística. in. MUSSALIN, Fernanda; BENTES, Anna Christina. (orgs.) Introdução à linguística: fundamentos epistemológicos: volume 3. 5.ed. São Paulo: Cortez, 2011.

POSSENTE, Sírio. Por que (não) ensinar gramática na escola. Campinas: Mercado das Letras, 1996.

ROCHA LIMA, Carlos Henrique da. Gramática Normativa da Lingua Portuguesa, $15^{a}$ ed. Rio de Janeiro: José Olympio, 1972.

SAUSSURE, Ferdinand de. Curso de Linguística Geral. 9a ed. São Paulo: Cultrix, s/d.

WEEDWOOD, Barbara. História concisa da linguística. São Paulo: Parábola Editorial, 2002.

Submetido em 23/05/2019

Aceito em 11/07/2019

Publicado em 05/08/2019 